\title{
Management of COPD in the UK primary-care setting: an analysis of real-life prescribing patterns
}

This article was published in the following Dove Press journal:

International Journal of COPD

27 August 2014

Number of times this article has been viewed

\author{
David Price' \\ Daniel West ${ }^{2}$ \\ Guy Brusselle $e^{3-5}$ \\ Kevin Gruffydd-Jones ${ }^{6}$ \\ Rupert Jones ${ }^{7}$ \\ Marc Miravitlles ${ }^{8}$ \\ Andrea Rossi ${ }^{9}$ \\ Catherine Hutton ${ }^{2}$ \\ Valerie L Ashton ${ }^{2}$ \\ Rebecca Stewart ${ }^{2}$ \\ Katsiaryna Bichel ${ }^{2}$ \\ 'Centre of Academic Primary Care, \\ University of Aberdeen, Aberdeen, UK; \\ ${ }^{2}$ Research in Real-Life Ltd, Cambridge, \\ UK; ${ }^{3}$ Department of Respiratory \\ Medicine, Ghent University Hospital, \\ Ghent, Belgium; ${ }^{4}$ Department of \\ Epidemiology, ${ }^{5}$ Department of \\ Respiratory Medicine, Erasmus \\ Medical Center, Rotterdam, the \\ Netherlands; ${ }^{6}$ Box Surgery, Wiltshire, \\ UK; ${ }^{7}$ Centre for Clinical Trials and \\ Health Research - Translational \\ and Stratified Medicine, Plymouth \\ University Peninsula Schools of \\ Medicine and Dentistry, Plymouth \\ UK; ${ }^{8}$ Department of Pneumology, \\ Hospital Universitari Vall d'Hebron, \\ Ciber de Enfermedades Respiratorias \\ (CIBERES), Barcelona, Spain; \\ ${ }^{9}$ Pulmonary Unit, Cardiovascular and \\ Thoracic Department, University and \\ General Hospital, Verona, Italy
}

Correspondence: David Price Centre of Academic Primary Care, University of Aberdeen, Polwarth Building, Foresterhill, Aberdeen AB25 2ZD, UK

Tel +442081233923

Fax +44808 2800792

Email david@rirl.org
Background: Despite the availability of national and international guidelines, evidence suggests that chronic obstructive pulmonary disease (COPD) treatment is not always prescribed according to recommendations. This study evaluated the current management of patients with COPD using a large UK primary-care database.

Methods: This analysis used electronic patient records and patient-completed questionnaires from the Optimum Patient Care Research Database. Data on current management were analyzed by the Global Initiative for Chronic Obstructive Lung Disease (GOLD) group and presence or absence of a concomitant asthma diagnosis, in patients with a COPD diagnosis at $\geq 35$ years of age and with spirometry results supportive of the COPD diagnosis.

Results: A total of 24,957 patients were analyzed, of whom 13,557 (54.3\%) had moderate airflow limitation (GOLD Stage 2 COPD). The proportion of patients not receiving pharmacologic treatment for COPD was $17.0 \%$ in the total COPD population and $17.7 \%$ in the GOLD Stage 2 subset. Approximately $50 \%$ of patients in both cohorts were receiving inhaled corticosteroids (ICS), either in combination with a long-acting $\beta_{2}$-agonist (LABA; 26.7\% for both cohorts) or a LABA and a long-acting muscarinic antagonist (LAMA; $23.2 \%$ and $19.9 \%$, respectively). ICS + LABA and ICS + LABA + LAMA were the most frequently used treatments in GOLD Groups A and B. Of patients without concomitant asthma, $53.7 \%$ of the total COPD population and $50.2 \%$ of the GOLD Stage 2 subset were receiving ICS. Of patients with GOLD Stage 2 COPD and no exacerbations in the previous year, $49 \%$ were prescribed ICS. A high proportion of GOLD Stage 2 COPD patients were symptomatic on their current management $(36.6 \%$ with modified Medical Research Council score $\geq 2 ; 76.4 \%$ with COPD Assessment Test score $\geq 10$ ).

Conclusion: COPD is not treated according to GOLD and National Institute for Health and Care Excellence recommendations in the UK primary-care setting. Some patients receive no treatment despite experiencing symptoms. Among those on treatment, most receive ICS irrespective of severity of airflow limitation, asthma diagnosis, and exacerbation history. Many patients on treatment continue to have symptoms.

Keywords: COPD, UK primary-care setting, prescribing patterns, inhaled corticosteroids, bronchodilators

\section{Introduction}

Chronic obstructive pulmonary disease (COPD) is a complex disease characterized by pulmonary as well as extrapulmonary effects. As airflow limitation poorly relates to other important clinical outcomes in COPD, the Global Initiative for Chronic Obstructive Lung Disease (GOLD) 2014 strategy advocates a combined assessment to estimate current symptoms and future risk of exacerbations (Figure S1). ${ }^{1}$ In the UK, 
the National Institute for Health and Care Excellence (NICE) also recommends a multidimensional assessment to guide treatment of COPD. ${ }^{2}$

In COPD, pharmacologic therapy is used to reduce symptoms, reduce frequency and severity of exacerbations, and improve health status and exercise tolerance. ${ }^{1}$ Bronchodilator medications are central to the pharmacologic management of COPD. ${ }^{1}$ Short-acting bronchodilators are used for immediate relief from symptoms; one or more long-acting bronchodilators (long-acting $\beta_{2}$-agonists [LABAs] or long-acting muscarinic antagonists [LAMAs]) are recommended for long-term maintenance therapy in patients with moderateto-severe COPD. ${ }^{1-3}$ Combining bronchodilators of different pharmacologic classes has the potential to improve efficacy, without increasing the risk of side effects, compared with increasing the dose of a single bronchodilator. ${ }^{1,4-7}$

Whilst inhaled corticosteroids (ICS) are the cornerstone of asthma management, their role in COPD remains controversial. $^{8-11}$ In COPD, the role of ICS is primarily to reduce the risk of exacerbations. ${ }^{12}$ Evidence from subset analyses of large clinical trials indicates the efficacy of LABA/ICS in patients with moderate or severe COPD, ${ }^{13}$ but the benefit due to the ICS component appears small compared with that of the LABA component. ${ }^{11,12}$ Further, the use of ICS has been associated with local and systemic side effects, including skin thinning and easy bruising, ${ }^{12}$ oral candidiasis, ${ }^{12,13}$ increased risk of pneumonia, ${ }^{12-15}$ osteoporosis, early onset diabetes, cataracts, ${ }^{12}$ and tuberculosis. ${ }^{16}$

The GOLD 2014 strategy recommends the addition of a second bronchodilator in symptomatic patients with moderate airflow limitation, reserving the use of ICS, in addition to a maintenance therapy with a LABA, and/or a LABA and a LAMA, for patients with severe or very severe airflow limitation and/or two or more exacerbations per year. ${ }^{1}$ In line with GOLD, national guidelines such as those developed by NICE recommend ICS in addition to a LABA as first choice in patients with severe airflow limitation (forced expiratory volume in 1 second $\left[\mathrm{FEV}_{1}\right]<50 \%$ of predicted) and recurrent exacerbations and/or breathlessness. ${ }^{2}$ However, there is evidence to suggest that treatment is not always prescribed according to GOLD recommendations or other national guidelines, ${ }^{9,17-22}$ resulting in a substantial proportion of patients being treated with ICS unnecessarily and unduly exposed to the risk of serious side effects.

The objective of this study was to evaluate the current management of patients with COPD using real-life data generated in the UK primary-care setting. The study also includes a subset analysis of patients with moderate airflow limitation ( $\mathrm{FEV}_{1} \geq 50-<80 \%$ predicted) as defined by NICE 2010 guidelines, which corresponds to GOLD Stage $2 .{ }^{23}$ This population forms the majority of patients treated in primary care, and is therefore relevant in this analysis of prescribing patterns of UK general practitioners.

\section{Methods}

Data for patients with a diagnosis of COPD were extracted from the Optimum Patient Care Research Database (OPCRD) on May 20, 2013. Only data for patients with a COPD diagnosis (quality and outcomes framework diagnostic code), ${ }^{24} 1$ year of practice data prior to last data extraction and no leaving date, spirometry supportive of COPD diagnosis within 5 years of data extraction, and last data extraction date after 2009 were included in this retrospective analysis. Data from patients younger than 35 years at diagnosis were excluded.

The OPCRD is a quality-controlled, longitudinal, primary-care, respiratory-focused database containing anonymous data from general practices in the UK. The OPCRD has been approved by Trent Multicentre Research Ethics Committee for clinical research use (approval reference 10/H0405/3). The database combines routine data from electronic patient records with linked patientreported data collected using disease-specific questionnaires. Routine clinical data, including patient demographics, standard COPD comorbidities, exacerbation history, modified Medical Research Council (mMRC) score, ${ }^{1}$ and current therapy, were extracted from primary-care practice management systems. In addition, a proportion of patients with relevant disease codes were invited to complete validated disease assessment questionnaires, sent via a secure mailing house, containing questions to calculate COPD Assessment Test $(\mathrm{CAT})^{25}$ and mMRC scores. Questionnaire data were added to the database anonymously. The mMRC questionnaire and CAT are provided in the supplementary materials (Figures S2 and S3).

Data were analyzed according to GOLD group ${ }^{26}$ and presence or absence of a concomitant asthma diagnosis. In a subset of patients with moderate airflow limitation, ${ }^{2,23}$ data were also analyzed by exacerbation history (moderate and severe exacerbation rate), mMRC score, and CAT score. mMRC scores were taken both from routine data (ie, abstracted from the medical record) and patient questionnaires, with the most recent scores taking precedence. CAT scores were obtained from patient questionnaires. GOLD groups were calculated with mMRC rather than CAT scores, unless specified otherwise. 
Moderate and severe COPD exacerbations were defined as unscheduled hospital admission/emergency hospital attendance for COPD (definite code) or lower respiratory-related events (ie, with a lower respiratory read code), or lower respiratory illnesses treated with antibiotics and/or acute use of oral steroids. Exacerbation rates were calculated for the year prior to most recent data extraction. Events were considered to be the result of the same exacerbation and only counted once if any of the three elements (hospitalization, oral steroid prescription, or lower respiratory tract infection consultation) occurred within 2 weeks of another.

\section{Results \\ Patient selection}

Data from 50,582 patients with COPD were extracted from 339 practices. Among these patients, 24,957 (49.3\%) met the inclusion criteria and were included in the analysis (Figure 1). Out of all the patients included in the analysis, 12,967 (52.0\%) were sent questionnaires, which were returned by 6,088 patients (46.9\%). The GOLD Stage 2 subset included 13,557 patients; 7,055 were sent a questionnaire, and 3,333 (47.2\%) returned the questionnaire.

\section{Demographics}

The mean age of the total COPD population was 71.4 years; the majority of patients were $<75$ years of age $(59.7 \%)$, male (53.0\%), and ex-smokers (56.2\%) (Table 1). The distribution of patients according to GOLD stages was $15.8 \%$ in Stage 1, $54.3 \%$ in Stage 2, 24.6\% in Stage 3, and 5.3\% in Stage 4. Based on degree of airflow limitation, symptoms (mMRC score), and history of exacerbations, the 23,294 (93.3\%) patients with known mMRC score were identified as being in GOLD Group A (39.2\%), Group B (20.0\%), Group C (19.0\%), or Group D (21.7\%). Of the patients in the highrisk groups, $\mathrm{C}$ and $\mathrm{D}, 57.6 \%$ and $59.2 \%$, respectively, were categorized as high risk based on severity of airflow limitation and not exacerbation history. The use of CAT score to assess symptoms resulted in a different distribution, with $13.4 \%, 46.1 \%, 4.6 \%$, and $35.9 \%$ of the 5,882 (23.6\%) patients with known CAT score classified as Group A, B, C, or D, respectively. There were no major demographic differences across GOLD groups in terms of age, sex, and smoking status (Table 1). The prevalence of comorbidities was similar across GOLD groups, except for ischemic heart disease, which was more prevalent in patients in Groups B and D (Table 1). The combined percentage of overweight and obese patients was higher in Group B than in any other GOLD group.

Demographic characteristics of patients with GOLD Stage 2 COPD were similar to those of patients in the total COPD population (Table 2). The mean age was 70.9 years and $52.2 \%$ of patients were male. The majority of patients (54.7\%) were ex-smokers. The most frequently occurring comorbidities in patients with GOLD Stage 2 COPD were the same as in the total COPD population. Patients with

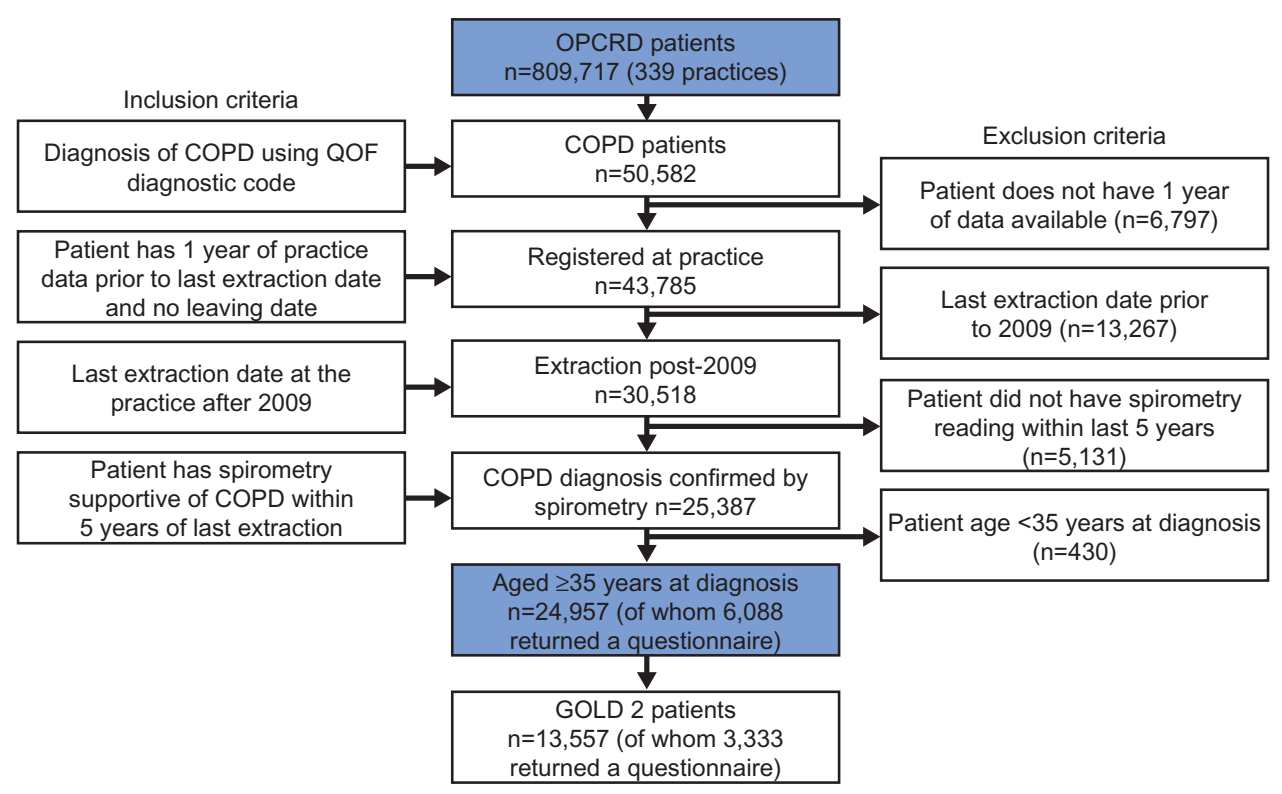

Figure I Patient selection.

Note: Data were extracted in May 2013.

Abbreviations: COPD, chronic obstructive pulmonary disease; GOLD, Global Initiative for Chronic Obstructive Lung Disease; OPCRD, Optimum Patient Care Research Database; QOF, quality and outcomes framework. 
Table I Patient demographics for the total COPD population split by GOLD group

\begin{tabular}{|c|c|c|c|c|c|c|}
\hline & $\begin{array}{l}\text { Total COPD } \\
\text { population } \\
(n=24,957)\end{array}$ & $\begin{array}{l}\text { Unknown } \\
\text { GOLD group } \\
(n=I, 663)\end{array}$ & $\begin{array}{l}\text { GOLD A } \\
(n=9,140)\end{array}$ & $\begin{array}{l}\text { GOLD B } \\
(n=4,65 I)\end{array}$ & $\begin{array}{l}\text { GOLD C } \\
(n=4,437)\end{array}$ & $\begin{array}{l}\text { GOLD D } \\
(n=5,066)\end{array}$ \\
\hline Mean age, ${ }^{a}$ years (SD) & $71.4(10.7)$ & $69.7(11.8)$ & $69.7(10.6)$ & $74.1(10.8)$ & $70.7(10.1)$ & $73.1(10.0)$ \\
\hline Age $<60$ & $3,352(13.4)$ & $326(19.6)$ & $1,540(16.8)$ & $468(10.1)$ & $567(12.8)$ & $45 I(8.9)$ \\
\hline Age $\geq 60-<75$ & II,558 (46.3) & $745(44.8)$ & $4,484(49.1)$ & $\mathrm{I}, 80 \mathrm{I}(38.7)$ & $2,273(51.2)$ & $2,255(44.5)$ \\
\hline Age $\geq 75$ & I0,047 (40.3) & $592(35.6)$ & $3,116(34.1)$ & $2,382(5 । .2)$ & I,597 (36.0) & $2,360(46.6)$ \\
\hline Male, n (\%) & $13,2 \mid 8(53.0)$ & $812(48.8)$ & $4,889(53.5)$ & $2,249(48.4)$ & $2,526(56.9)$ & $2,742(54.1)$ \\
\hline \multicolumn{7}{|l|}{$\begin{array}{l}\text { GOLD stage (GOLD 20।3), } \\
\text { n (\%) }\end{array}$} \\
\hline I & $3,937(15.8)$ & $414(24.9)$ & $2,136(23.4)$ & $888(19.1)$ & $305(6.9)$ & $194(3.8)$ \\
\hline 2 & I3,557 (54.3) & $827(49.7)$ & $7,004(76.6)$ & $3,763(80.9)$ & $1,065(24.0)$ & $898(17.7)$ \\
\hline 3 & $6,137(24.6)$ & $338(20.3)$ & $0(0)$ & $0(0)$ & $2,669(60.2)$ & $3,130(6 \mid .8)$ \\
\hline 4 & I,326 (5.3) & $84(5.1)$ & $0(0)$ & $0(0)$ & $3,98(9.0)$ & $844(16.7)$ \\
\hline \multicolumn{7}{|l|}{ Smoking status, ${ }^{\mathrm{b}} \mathrm{n}(\%)$} \\
\hline Known & $24,947(100.0)$ & $1,663(100)$ & $9,138(100)$ & $4,651(100)$ & 4,434 (99.9) & $5,061(99.9)$ \\
\hline Current smoker & $7,608(30.5)$ & $584(35.1)$ & $3,034(33.2)$ & I,365 (29.3) & I,345 (30.3) & $\mathrm{I}, 280(25.3)$ \\
\hline Ex-smoker & $|4,0| 8(56.2)$ & 797 (47.9) & $4,824(52.8)$ & 2,691 (57.9) & $2,527(57.0)$ & $3,179(62.8)$ \\
\hline Nonsmoker & $3,32 \mid(\mid 3.3)$ & $282(17.0)$ & $\mathrm{I}, 280(\mid 4.0)$ & $595(12.8)$ & $562(12.7)$ & 602 (II.9) \\
\hline \multicolumn{7}{|l|}{ Body mass index, ${ }^{\mathrm{c}} \mathrm{n}(\%)$} \\
\hline Known & $24,646(98.8)$ & I,64I (98.7) & $9,054(99.1)$ & $4,604(99.0)$ & $4,365(98.4)$ & $4,982(98.3)$ \\
\hline Underweight & $\mathrm{I}, 06 \mathrm{I}(4.3)$ & $78(4.8)$ & $245(2.7)$ & $179(3.9)$ & $220(5.0)$ & $339(6.8)$ \\
\hline Normal weight & $8,246(33.5)$ & $543(33.1)$ & $2,979(32.9)$ & $1,260(27.4)$ & I,697 (38.9) & $\mathrm{I}, 767(35.5)$ \\
\hline Overweight & $8,290(33.6)$ & $547(33.3)$ & $3,398(37.5)$ & $1,420(30.8)$ & $1,463(33.5)$ & $\mathrm{I}, 462(29.3)$ \\
\hline Obese & $7,049(28.6)$ & $473(28.8)$ & $2,432(26.9)$ & $1,745(37.9)$ & $985(22.6)$ & $\mathrm{I}, 4 \mid 4(28.4)$ \\
\hline \multicolumn{7}{|l|}{ Comorbidities, ${ }^{d}$ n (\%) } \\
\hline Anxiety or depression & $7,621(30.5)$ & $573(34.5)$ & $2,644(28.9)$ & I,607 (34.6) & I,205 (27.2) & I,592 (3I.4) \\
\hline Asthma & $7,027(28.2)$ & $536(32.2)$ & $2,464(27.0)$ & $1,262(27.1)$ & I,28I (28.9) & I,484 (29.3) \\
\hline Diabetes & $4,592(I 8.4)$ & $268(16.1)$ & $1,545(16.9)$ & $1,028(22.1)$ & $764(17.2)$ & $987(19.5)$ \\
\hline $\begin{array}{l}\text { Chronic kidney disease } \\
\text { (stage } \geq 3 \text { ) }\end{array}$ & $4,373(17.5)$ & $264(15.9)$ & I,278 (I4.0) & $\mathrm{I}, \mathrm{I} 65(25.0)$ & $622(14.0)$ & $\mathrm{I}, 044(20.6)$ \\
\hline Ischemic heart disease & $4,114(16.5)$ & $229(13.8)$ & $\mathrm{I}, 145(12.5)$ & $\mathrm{I}, \mathrm{I} 32(24.3)$ & $572(12.9)$ & $\mathrm{I}, 036(20.5)$ \\
\hline Osteoporosis & $3,373(13.5)$ & $208(12.5)$ & $960(10.5)$ & $76 I(16.4)$ & $538(12.1)$ & $906(17.9)$ \\
\hline Rhinitis & $3,099(12.4)$ & $230(13.8)$ & $\mathrm{I}, 17 \mathrm{I}(12.8)$ & $521(11.2)$ & $586(13.2)$ & 591 (II.7) \\
\hline GERD & $2,78 \mid(I I . I)$ & $210(12.6)$ & $1,005(11.0)$ & $577(12.4)$ & $450(10.1)$ & $539(10.6)$ \\
\hline Heart failure & I,833 (7.3) & $86(5.2)$ & $427(4.7)$ & $546(11.7)$ & $252(5.7)$ & $522(10.3)$ \\
\hline History of pneumonia, n (\%) & $2,102(8.4)$ & $133(8.0)$ & $568(6.2)$ & $388(8.3)$ & $409(9.2)$ & $604(11.9)$ \\
\hline
\end{tabular}

Notes: GOLD groups calculated based on mMRC score, FEV , and history of exacerbations. For smoking status and body mass index, percentages were calculated based

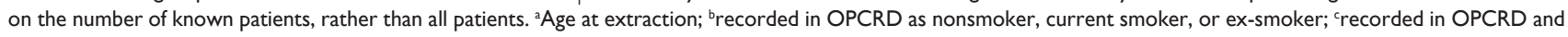
calculated as mass $(\mathrm{kg}) /$ height $\left(\mathrm{m}^{2}\right)$; underweight $<18.5 \mathrm{~kg} / \mathrm{m}^{2} ;$ normal weight between $\geq 18.5$ and $<25 \mathrm{~kg} / \mathrm{m}^{2}$, overweight between $\geq 25$ and $<30 \mathrm{~kg} / \mathrm{m}^{2}$, obese $\geq 30 \mathrm{~kg} / \mathrm{m}^{2}$; 'all comorbidities defined as having a diagnostic code in patients' medical history.

Abbreviations: COPD, chronic obstructive pulmonary disease; FEV, forced expiratory volume in I second; GERD, gastro-esophageal reflux disease; GOLD, Global Initiative for Chronic Obstructive Lung Disease; mMRC, modified Medical Research Council; OPCRD, Optimum Patient Care Research Database; SD, standard deviation.

known GOLD groups ( $\mathrm{n}=12,730)$ were identified as being in Group A (55.0\%), Group B (29.6\%), Group C (8.4\%), or Group D (7.1\%) based on mMRC score. Patients $(n=3,227)$ were classified as being in Group A (18.7\%), Group B (67.2\%), Group C (2.0\%), or Group D (12.2\%) when symptoms were assessed using CAT score.

Demographic characteristics of patients who were responders and nonresponders to the study questionnaires are illustrated in the supplementary materials (Table S1) for total COPD population and GOLD Stage 2 subset. Overall, patients who returned the questionnaire, as compared with those who did not, tended to be slightly older (72.4 versus
70.5 years) and were more likely to be male (56.1\% versus $52.5 \%)$ and ex-smokers (61.7\% versus $52.1 \%$ ) but less likely to be current smokers (24.7\% versus $33.8 \%$ ); differences in GOLD group categorization were minor. A similar pattern was evident for patients categorized at GOLD Stage 2 who did, versus did not, return the questionnaire (Table S1).

\section{Clinical characteristics}

Of the patients in the total COPD population, $61.0 \%$ had no exacerbations and $16.9 \%$ had two or more moderate or severe exacerbations in the year prior to data extraction. The majority of patients with no exacerbations were in 
Table 2 Patient demographics for the GOLD Stage 2 population split by GOLD group

\begin{tabular}{|c|c|c|c|c|c|}
\hline & $\begin{array}{l}\text { GOLD Stage } 2 \\
\text { population } \\
(n=13,557)\end{array}$ & $\begin{array}{l}\text { GOLD A } \\
(n=7,004)\end{array}$ & $\begin{array}{l}\text { GOLD B } \\
(n=3,763)\end{array}$ & $\begin{array}{l}\text { GOLD C } \\
(n=1,065)\end{array}$ & $\begin{array}{l}\text { GOLD D } \\
(n=898)\end{array}$ \\
\hline Mean age, ${ }^{a}$ years (SD) & $70.9(10.9)$ & $69.6(10.5)$ & $73.8(10.8)$ & $69.6(10.2)$ & $72.0(10.7)$ \\
\hline Age $<60$ & I,988 (I4.7) & $1,164(16.6)$ & $387(10.3)$ & $152(14.3)$ & $108(12.0)$ \\
\hline Age $\geq 60-<75$ & $6,331(46.7)$ & $3,482(49.7)$ & I,50| (39.9) & $569(53.4)$ & 409 (45.5) \\
\hline Age $\geq 75$ & $5,238(38.6)$ & $2,358(33.7)$ & $\mathrm{I}, 875(49.8)$ & $344(32.3)$ & $381(42.4)$ \\
\hline Male, n (\%) & $7,082(52.2)$ & 3,88I (55.4) & $1,890(50.2)$ & $517(48.5)$ & $381(42.4)$ \\
\hline \multicolumn{6}{|l|}{ Smoking status, ${ }^{\text {b }}$ (\%) } \\
\hline Known & I3,554 (I00.0) & $7,003(100.0)$ & $3,763(100.0)$ & I,064 (99.9) & 897 (99.9) \\
\hline Current smoker & $4,413(32.6)$ & $2,361(33.7)$ & $\mathrm{I}, 135(30.2)$ & $355(33.4)$ & $257(28.7)$ \\
\hline Ex-smoker & $7,414(54.7)$ & $3,744(53.5)$ & $2,200(58.5)$ & $570(53.6)$ & $516(57.5)$ \\
\hline Nonsmoker & I,727 (I2.7) & $898(12.8)$ & $428(11.4)$ & $139(13.1)$ & $124(13.8)$ \\
\hline \multicolumn{6}{|l|}{ Body mass index, ${ }^{c} \mathrm{n}(\%)$} \\
\hline Known & $13,4 \mid 2$ (98.9) & $6.931(99.0)$ & $3,720(98.9)$ & I,052 (98.8) & 888 (98.9) \\
\hline Underweight & $452(3.4)$ & $188(2.7)$ & $154(4.1)$ & $40(3.8)$ & $32(3.6)$ \\
\hline Normal weight & $4,186(3 \mid .2)$ & $2,265(32.7)$ & $1,030(27.7)$ & $345(32.8)$ & $275(31.0)$ \\
\hline Overweight & $4,628(34.5)$ & $2,577(37.2)$ & $1,153(31.0)$ & $396(37.6)$ & $230(25.9)$ \\
\hline Obese & $4,146(30.9)$ & $\mathrm{I}, 90 \mathrm{I}(27.4)$ & I,383 (37.2) & $271(25.8)$ & 351 (39.5) \\
\hline \multicolumn{6}{|l|}{ Comorbidities, ${ }^{d}$ n (\%) } \\
\hline Anxiety or depression & $4,254(31.4)$ & I,972 (28.2) & $1,279(34.0)$ & $340(31.9)$ & $391(43.5)$ \\
\hline Asthma & $3,743(27.6)$ & I,840 (26.3) & $1,015(27.0)$ & $326(30.6)$ & $299(33.3)$ \\
\hline Diabetes & $2,576(19.0)$ & $\mathrm{I}, 224(17.5)$ & $856(22.7)$ & $163(15.3)$ & $200(22.3)$ \\
\hline $\begin{array}{l}\text { Chronic kidney disease } \\
\text { (stage } \geq 3 \text { ) }\end{array}$ & $2,38 I(I 7.6)$ & $969(13.8)$ & $927(24.6)$ & $164(15.4)$ & $198(22.0)$ \\
\hline Ischemic heart disease & $2,268(16.7)$ & $894(12.8)$ & $927(24.6)$ & $130(12.2)$ & $199(22.2)$ \\
\hline Rhinitis & $1,754(12.9)$ & $863(12.3)$ & $413(11.0)$ & $213(20.0)$ & $144(16.0)$ \\
\hline Osteoporosis & $1,700(12.5)$ & $695(9.9)$ & $580(15.4)$ & $134(12.6)$ & $206(22.9)$ \\
\hline GERD & I,536 (II.3) & $74 \mid(10.6)$ & $437(11.6)$ & $|3|(\mid 2.3)$ & $131(14.6)$ \\
\hline Heart failure & $965(7.1)$ & $333(4.8)$ & 448 (11.9) & $53(5.0)$ & $89(9.9)$ \\
\hline History of pneumonia, n (\%) & $1,089(8.0)$ & $448(6.4)$ & $318(8.5)$ & $125(11.7)$ & $139(15.5)$ \\
\hline
\end{tabular}

Notes: GOLD groups calculated based on mMRC score, FEV , and history of exacerbations. For smoking status and body mass index, percentages were calculated based on the number of known patients, rather than all patients. ${ }^{\mathrm{a} A g e}$ at extraction; ${ }^{\mathrm{b}}$ recorded in OPCRD as nonsmoker, current smoker, or ex-smoker; ${ }^{\mathrm{r} r e c o r d e d}$ in OPCRD and calculated as mass $(\mathrm{kg}) /$ height $\left(\mathrm{m}^{2}\right)$; underweight $<18.5 \mathrm{~kg} / \mathrm{m}^{2}$, normal weight between $\geq 18.5$ and $<25 \mathrm{~kg} / \mathrm{m}^{2}$, overweight between $\geq 25$ and $<30 \mathrm{~kg} / \mathrm{m}^{2}$, obese $\geq 30 \mathrm{~kg} / \mathrm{m}^{2}$; dall comorbidities defined as having a diagnostic code in patients' medical history.

Abbreviations: COPD, chronic obstructive pulmonary disease; FEV , forced expiratory volume in I second; GERD, gastro-esophageal reflux disease; GOLD, Global Initiative for Chronic Obstructive Lung Disease; mMRC, modified Medical Research Council; OPCRD, Optimum Patient Care Research Database; SD, standard deviation.

Group A (45.4\%), while $25.9 \%$ of patients were classified as being in Groups C or D based on severity of airflow limitation (Figure 2). Of the patients with exacerbations in the year prior to data extraction, $57.2 \%$ were in Groups $\mathrm{C}$ or D.

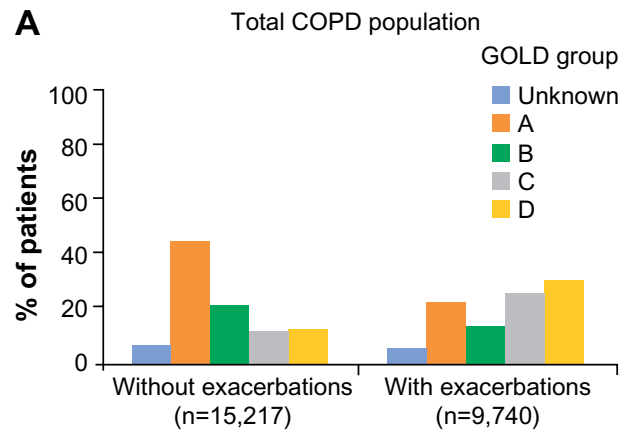

Patients with GOLD Stage 2 COPD displayed similar clinical characteristics to those in the overall cohort in terms of total exacerbation rate. In the GOLD Stage 2 subset, $62.4 \%$ of patients had no exacerbations and $15.4 \%$ had two or more moderate or severe exacerbations in the

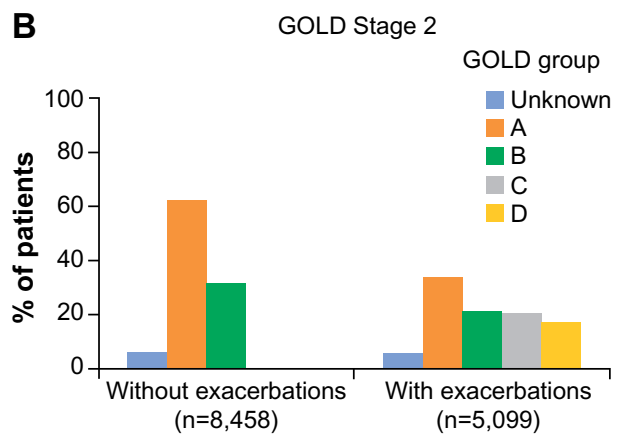

Figure 2 Distribution of GOLD groups in patients without and with moderate and severe exacerbations in the year prior to data extraction for total COPD population (A) and GOLD Stage 2 subset (B).

Note: GOLD groups calculated without COPD Assessment Test score.

Abbreviations: COPD, chronic obstructive pulmonary disease; GOLD, Global Initiative for Chronic Obstructive Lung Disease. 
year prior to data extraction. Of the patients with no exacerbations, $62.3 \%$ were classified as being in Group A and $31.5 \%$ were classified as being in Group B. The majority of patients with exacerbations in the year prior to data extraction were in Group A (34.0\%; Figure 2). However, $38.5 \%$ of patients were classified as being in Groups C or $\mathrm{D}$ and experienced two or more exacerbations in the year previous to data extraction, despite having moderate airflow limitation.

In the total COPD population, among patients with a known mMRC score, the mean (standard deviation [SD]) mMRC score was $1.5(1.0) ; 40.9 \%$ of patients had an mMRC score of 1 and $41.7 \%$ had a score $\geq 2$. In the GOLD Stage 2 subset, among patients with a known mMRC score, the mean (SD) mMRC score was 1.3 (1.0); $43.7 \%$ of patients had an mMRC score of 1 and $36.6 \%$ had a score $\geq 2$. Among patients who returned a questionnaire and had a known CAT score, the mean (SD) CAT score was 17.1 (9.0) in the total COPD population and 16.3 (8.9) in the GOLD Stage 2 subset. Of the patients with a known CAT score, $79.0 \%$ and $76.4 \%$ had a CAT score $\geq 10$ in the total COPD population and in the GOLD Stage 2 subset, respectively.

\section{Current management}

A similar proportion of patients in the total COPD population $(n=24,957)$ and GOLD Stage 2 subset $(n=13,557)$ were not receiving pharmacologic treatment for COPD (17.0\% and $17.7 \%$, respectively; Figure $3 \mathrm{~A}$ and $\mathrm{B})$. Approximately $50 \%$ of patients in the total COPD population and GOLD Stage 2 subset were receiving ICS (Figure 3A and B), either in combination with a LABA $(26.7 \%$ for both cohorts $)$ or in

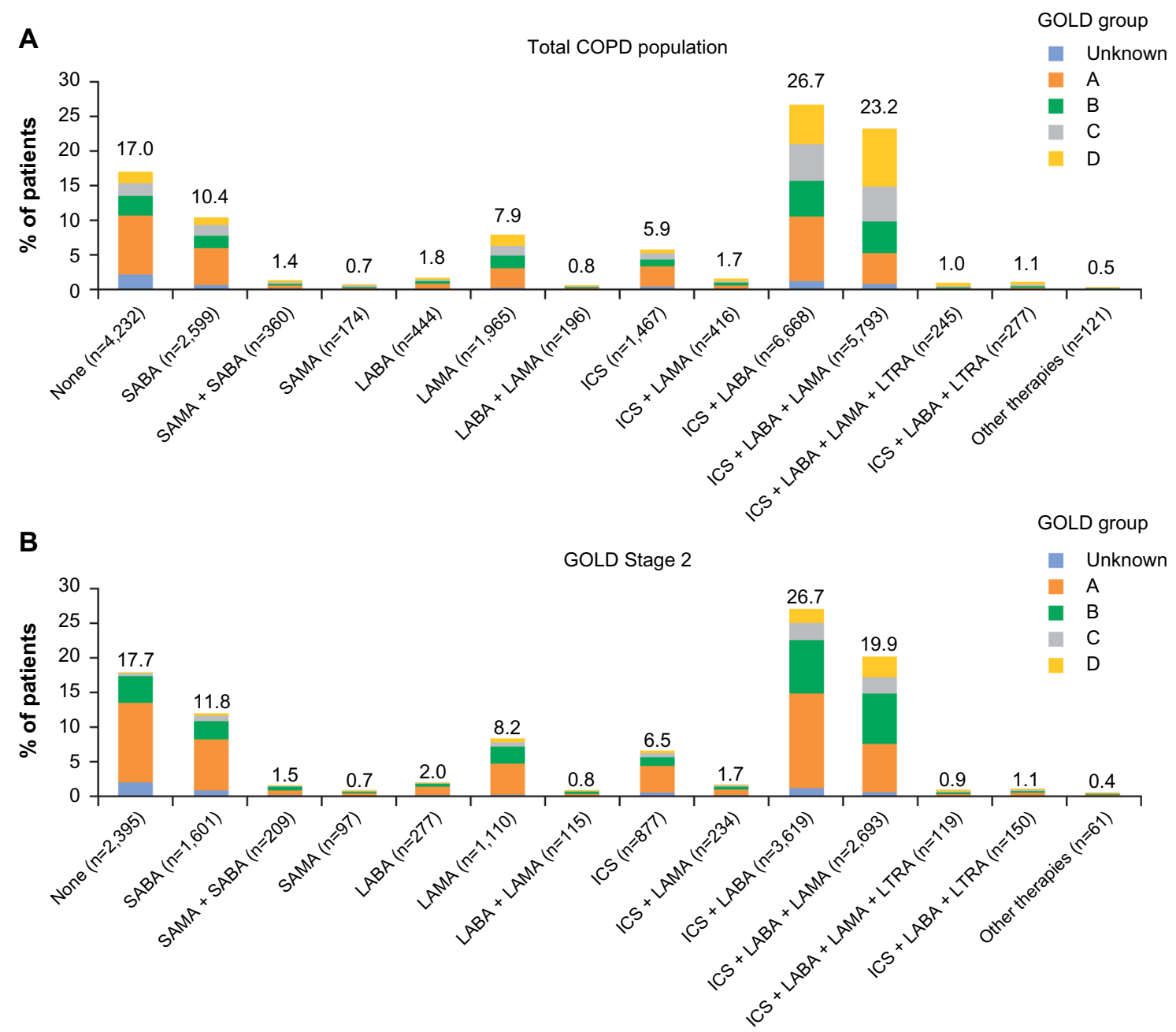

Figure 3 Current management for total COPD population (A) and GOLD Stage 2 subset (B) by GOLD groups.

Notes: Percentages were calculated against the total number of patients in the COPD population $(n=24,957)$ and GOLD Stage 2 subset $(n=13,557)$. Other therapies include other combinations of ICS, LAMA, LABA, SAMA, SABA, LTRA, and theophylline.

Abbreviations: COPD, chronic obstructive pulmonary disease; GOLD, Global Initiative for Chronic Obstructive Lung Disease; ICS, inhaled corticosteroids; LABA, long-acting $\beta_{2}$-agonist; LAMA, long-acting muscarinic antagonist; LTRA, leukotriene receptor antagonist; SAMA, short-acting muscarinic antagonist; SABA, short-acting $\beta_{2}$-agonist. 
combination with a LABA and a LAMA (23.2\% and 19.9\%, respectively). In both cohorts, ICS + LABA combinations were the most frequently used treatment in Groups A and B (Figure 3A and B). Of the total COPD population, 9.3\% and $5.1 \%$ of Group A and B patients were receiving ICS + LABA. Of the patients with GOLD Stage 2 COPD, 13.5\% and 7.6\% of Group A and B patients, respectively, were given ICS + LABA. A small proportion of patients across all GOLD groups were using LABA or LAMA monotherapy in the total COPD population (1.8\% and $7.9 \%$, respectively) and GOLD Stage 2 subset (2.0\% and 8.2\%; Figure $3 \mathrm{~A}$ and B).

Current management was analyzed based on the presence or absence of a concomitant asthma diagnosis. Of the patients without a concomitant diagnosis of asthma in the total COPD population $(n=17,930)$ and GOLD Stage 2 subset $(n=9,814)$ $53.7 \%$ and $50.2 \%$, respectively, were receiving ICS. Among ICS-containing regimens, ICS + LAMA, ICS + LABA, and
ICS + LABA + LAMA were the most frequently used treatment options (total COPD population: 70.7\%, 63.9\%, and $68.1 \%$, respectively; GOLD Stage 2 subset: $68.8 \%, 63.2 \%$, and $67.5 \%$, respectively; Figure $4 \mathrm{~A}$ and $\mathrm{B}$ ).

\section{GOLD Stage 2 subset analyses}

Additional analyses were conducted in the GOLD Stage 2 subset. Figure 5 illustrates current management by moderate and severe exacerbation rate. Among patients who experienced no exacerbations $(n=8,458)$ or one exacerbation $(n=3,006)$ in the year prior to extraction, $49.0 \%$ and $64.1 \%$, respectively, were receiving ICS, either alone or in combination with long-acting bronchodilators. Of those patients receiving no treatment, $87.3 \%$ experienced no exacerbations in the year prior to data extraction, while of those patients receiving triple therapy (ICS + LABA + LAMA or ICS + LABA + leukotriene receptor antagonist)
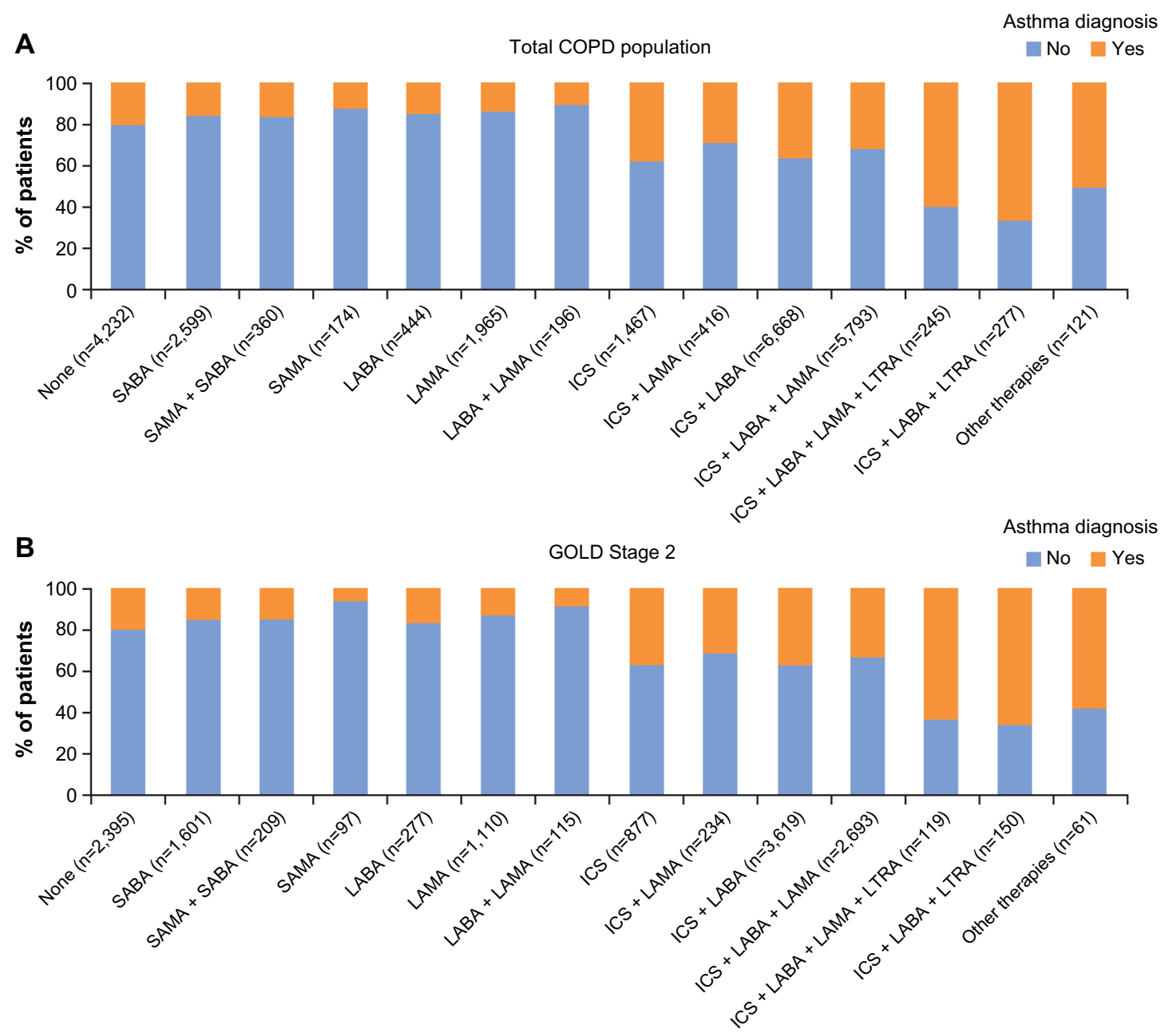

Figure 4 Current management by concomitant asthma diagnosis for total COPD population (A) and GOLD Stage 2 subset (B).

Note: Other therapies include other combinations of ICS, LAMA, LABA, SAMA, SABA, LTRA, and theophylline.

Abbreviations: COPD, chronic obstructive pulmonary disease; GOLD, Global Initiative for Chronic Obstructive Lung Disease; ICS, inhaled corticosteroids; LABA, long-acting $\beta_{2}$-agonist; LAMA, long-acting muscarinic antagonist; LTRA, leukotriene receptor antagonist; SAMA, short-acting muscarinic antagonist; SABA, short-acting $\beta_{2}$-agonist. 


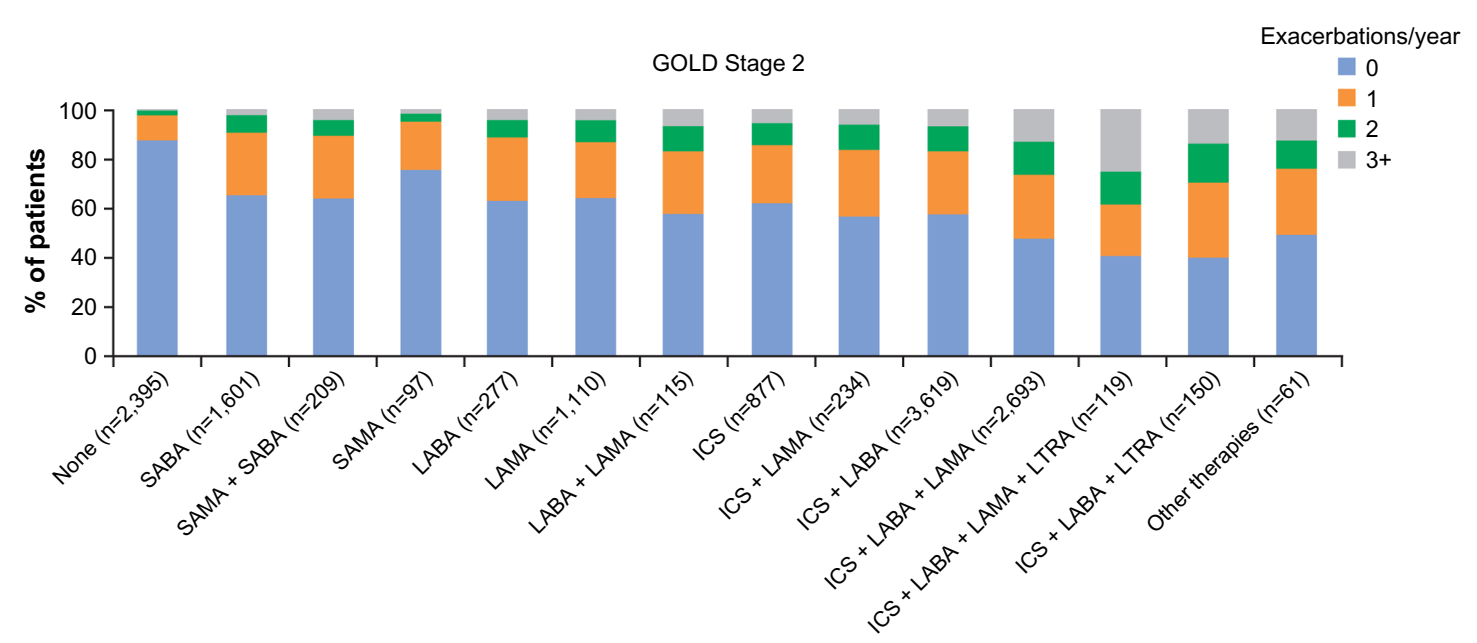

Figure 5 Current management by moderate and severe exacerbation rate in the year prior to data extraction for the GOLD Stage 2 subset. Note: Other therapies include other combinations of ICS, LAMA, LABA, SAMA, SABA, LTRA, and theophylline.

Abbreviations: GOLD, Global Initiative for Chronic Obstructive Lung Disease; ICS, inhaled corticosteroids; LABA, long-acting $\beta_{2}$-agonist; LAMA, long-acting muscarinic antagonist; LTRA, leukotriene receptor antagonist; SAMA, short-acting muscarinic antagonist; SABA, short-acting $\beta_{2}$-agonist.

or quadruple therapy (ICS + LABA + LAMA + leukotriene receptor antagonist), more than $50 \%$ experienced one or more exacerbations in the year prior to extraction (Figure 5).

Further, current management in the GOLD Stage 2 subset was analyzed based on mMRC and CAT scores to evaluate the proportion of patients experiencing symptoms while on treatment. An $\mathrm{mMRC}$ score $\geq 2$ was recorded for $22.7 \%$ of patients receiving no treatment, $35.4 \%$ of patients receiving LAMA monotherapy, and $35.6 \%$ and $50.2 \%$ of patients receiving ICS + LABA and ICS + LABA + LAMA, respectively (Figure 6A). A CAT score $\geq 10$ was recorded for $66.7 \%$ of patients receiving no treatment, $74.5 \%$ of patients on LAMA monotherapy, and $74.4 \%$ and $81.9 \%$ of patients receiving ICS + LABA and ICS + LABA + LAMA, respectively (Figure 6B).

\section{Discussion}

The present study, one of the largest to evaluate real-life treatment patterns of COPD in the UK, indicates that COPD is often not managed in primary care according to the most recent recommendations and guidelines. In our analysis, a substantial proportion of patients with COPD did not receive any treatment despite experiencing symptoms or a history of exacerbations. Among patients receiving treatment, ICS were prescribed to patients irrespective of severity of airflow limitation, exacerbation history, and asthma diagnosis.

NICE recommends a LABA/ICS combination for patients with severe airflow limitation $\left(\mathrm{FEV}_{1}<50 \%\right.$ predicted) and/or persistent exacerbations/breathlessness ${ }^{2}$ whereas the GOLD 2014 strategy document currently recommends LABA/ICS combinations for patients in Groups C and D. ${ }^{1}$
The only exception to these recommendations on the use of ICS is for patients with overlap phenotype of asthma and COPD, in whom ICS are indicated. ${ }^{9}$ Notably, a considerable proportion of patients in GOLD Groups A and B (mild-tomoderate airflow limitation and low risk of exacerbations) in the total COPD population, as well as in the GOLD Stage 2 subset, were using ICS in combination with longacting bronchodilators; conversely, only a small proportion of these patients were treated exclusively with long-acting bronchodilators, either as mono- or combination therapy. Consistent with this finding, approximately half of the patients who had not experienced an exacerbation in the year prior to data extraction were receiving ICS. The majority of patients without a concomitant diagnosis of asthma were also being treated with ICS, suggesting that ICS were overprescribed. In the total COPD population, $17 \%$ of patients were not receiving pharmacologic treatment for COPD. This is greater than the proportion of adults diagnosed with diabetes who have been reported to not use recommended oral medications or insulin (approximately 13\%), ${ }^{27}$ but is lower compared with other chronic diseases such as multiple sclerosis and hypertension in which between one-third and two-thirds of patients have been reported to receive no approved treatment for their conditions. ${ }^{28-31}$

Our findings are supported by several studies analyzing the adherence to recommendations and guidelines for the management of COPD. Recently, data from a retrospective study revealed that most patients with COPD use ICS, irrespective of airflow limitation and exacerbation rate. ${ }^{32}$ In addition, data from the Adelphi Respiratory Disease Specific Programme $^{\circledR}$ (Adelphi, Macclesfield, UK), a multinational, 
A GOLD Stage 2

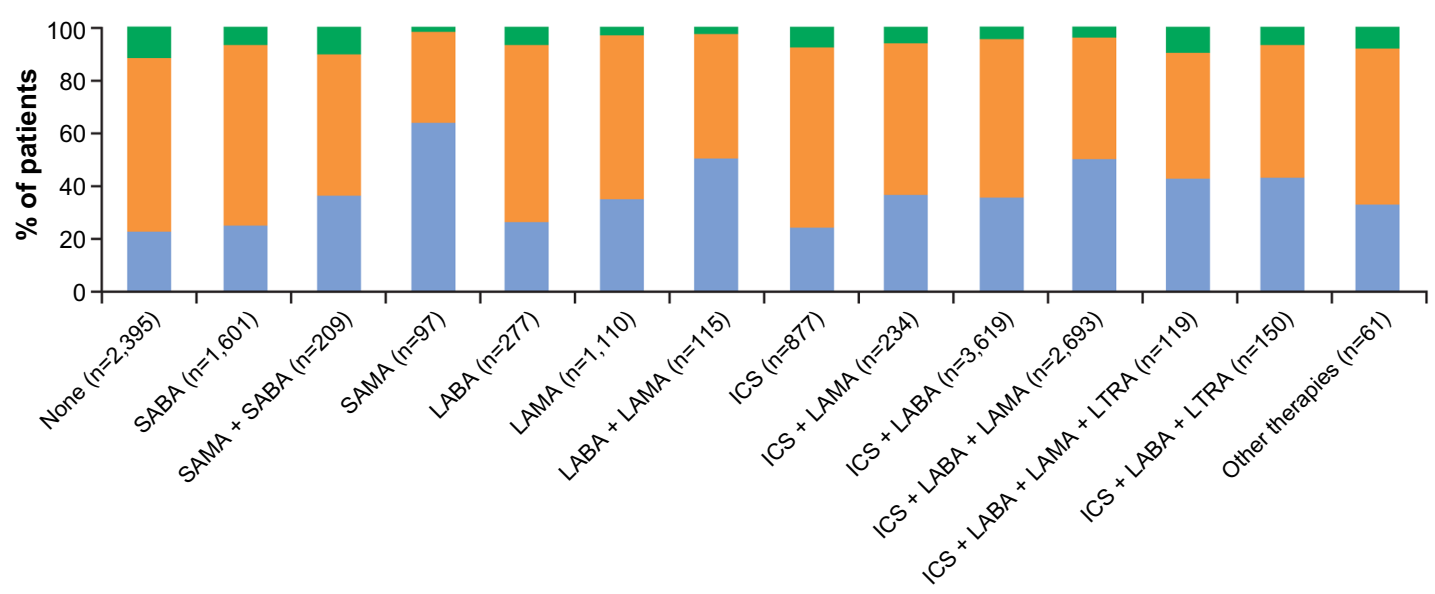

B

GOLD Stage 2

CAT 0-9 CAT $\geq 10 \quad$ Unknown

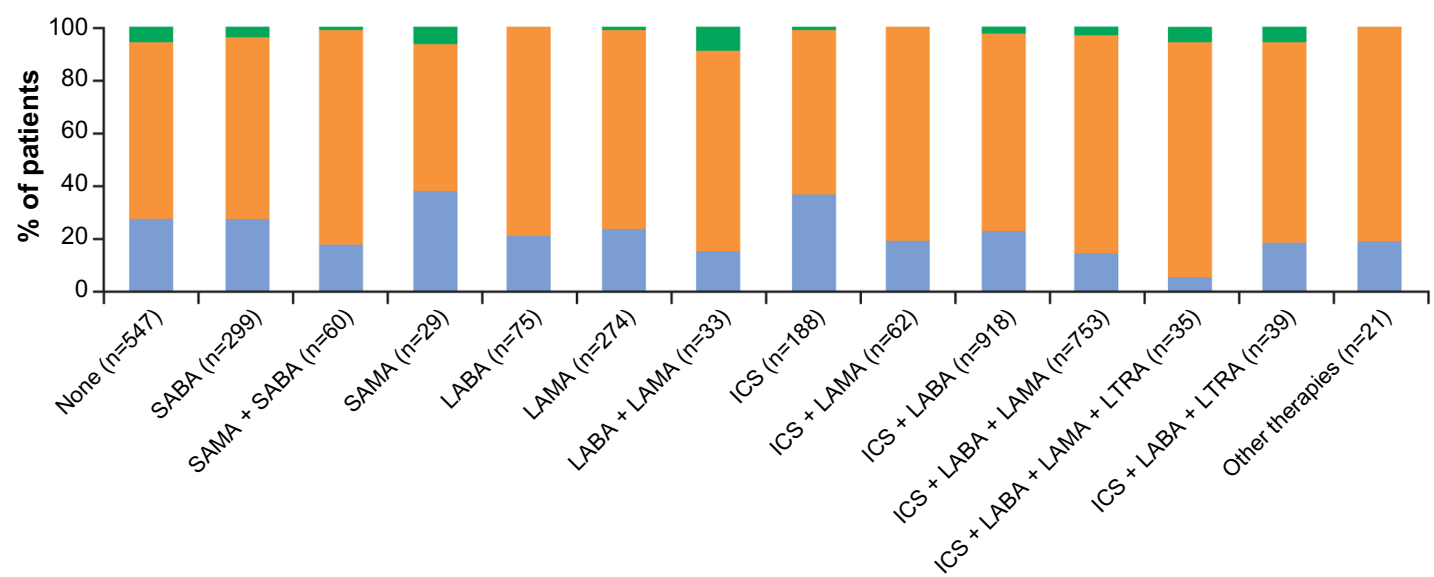

Figure 6 Current management by mMRC score (A) and CAT score (B) for the GOLD Stage 2 subset.

Notes: mMRC scores are taken from the most recent routine data or questionnaire data to the extraction date. Other therapies include other combinations of ICS, LAMA, LABA, SAMA, SABA, LTRA, and theophylline.

Abbreviations: CAT, COPD Assessment Test; COPD, chronic obstructive pulmonary disease; GOLD, Global Initiative for Chronic Obstructive Lung Disease; ICS, inhaled corticosteroids; LABA, long-acting $\beta_{2}$-agonist; LAMA, long-acting muscarinic antagonist; mMRC, modified Medical Research Council; LTRA, leukotriene receptor antagonist; SAMA, short-acting muscarinic antagonist; SABA, short-acting $\beta_{2}$-agonist.

cross-sectional market-research survey that generates data from current clinical practice, showed that a high proportion of low-risk patients are treated with a LABA/ICS. ${ }^{33}$ Studies in other European countries have also shown a tendency for ICS to be prescribed outside of current recommendations in COPD, indicating that poor adherence to treatment guidelines among primary-care physicians is widespread. . $, 20,22,34-37^{2}$

Several factors can contribute to this disconnect between current real-life practice and evidence-based treatment recommendations. Two studies assessing the management of COPD in the US recently highlighted several barriers to implementing GOLD recommendations in primary care. ${ }^{38,39}$
One important barrier identified by Perez et $\mathrm{al}^{38}$ was poor familiarity with GOLD recommendations, which was found to be associated with nonadherence to specific recommendations on ICS and long-acting bronchodilators. Further, the study by Salinas et a ${ }^{39}$ found that physicians who have difficulty assessing response to therapy were less likely to adhere to recommendations on long-acting bronchodilator use. As suggested by the authors of the study, this may be because long-acting bronchodilators produce subtle but meaningful improvements, which can be difficult for physicians to recognize. ${ }^{39}$ Moreover, physicians may not recognize a benefit of therapy in individual patients who have infrequent exacerbations, as 
decreased frequency of exacerbations is an important measure of the efficacy of inhaled therapies. Indeed, in our study, $61 \%$ of the total population did not experience an exacerbation in the preceding year, including many patients classified as being in Groups C and D. This makes the assessment of treatment benefit difficult for all severities of COPD.

Difficulties in distinguishing between asthma and COPD in adults with airways disease, or in establishing when these two conditions coexist, could also play an important role. The CADRE (COPD and asthma diagnostic/management reassessment) study among UK primary-care practices found a high rate of misdiagnosis among adults with airways disease, with a tendency to overdiagnose asthma and underdiagnose COPD. ${ }^{40}$ A high proportion of patients diagnosed with asthma $(54.3 \%)$ and mixed disease (45.4\%) had their diagnosis changed, with the majority of them diagnosed with COPD after review. These findings indicate a lack of precision in diagnosing the 'chesty' patient in primary care. Data from Spanish practices also confirm the difficulty of accurately diagnosing COPD in primary care. Primary-care physicians using clinical criteria and spirometry had difficulty reaching a diagnosis for up to $20 \%$ of patients with chronic respiratory symptoms who were taking inhaled medication. ${ }^{37}$ The misdiagnosis of respiratory disease may lead to inadequate treatment and overuse of ICS $^{21,22,37}$ particularly for patients with COPD.

The burden of symptoms reported by patients, which affects the physician-perceived severity of the disease, could also have a considerable impact on treatment choices. Physicians may evaluate disease as more or less severe based on their overall clinical judgment rather than guidelines. Physicians may, therefore, be more willing to prescribe treatments outside of recommendations when confronted by symptomatic patients, resulting in ICS being prescribed for reasons other than severity of airflow limitation or exacerbation risk. Indeed, a recent study of prescription drugs from UK general practices suggests that over $37 \%$ of COPD patients were overtreated (ie, according to GOLD 2009 recommendations) and, of those, $96 \%$ were overtreated with $\mathrm{ICS} .{ }^{41}$ As shown by our data, a substantial proportion of GOLD Stage 2 patients in the UK are symptomatic on treatment, irrespective of their current management. In line with our findings, studies have suggested that many patients with moderate COPD may remain symptomatic despite LAMA monotherapy ${ }^{42-44}$ or LABA/ICS treatment. ${ }^{45}$ Interestingly, our analysis suggests that use of CAT, compared with mMRC, increased the number of patients in more symptomatic groups (Groups B and D), potentially because the CAT assessment considers not only dyspnea, but also other COPD symptoms and health status. This difference in GOLD group distribution depending on whether the mMRC score or CAT score is used highlights the difficulty facing primary-care physicians when making treatment decisions in real-life practice and illustrates how guidelines may only provide limited assistance.

It is important to note that in some cases the discordance between the current treatment recommendations and real-life clinical practice may be because of individual patients' needs and comorbidities. Indeed, the NICE guidelines state that, "Treatment and care should take into account patients' needs and preferences." "2 In addition, our study provides a snapshot of current practice and may reflect therapy that has been longstanding and perceived as 'effective' by both the patient and physician. Thus, in some cases, depending on individual factors, it may be reasonable for patients to continue with existing therapy despite the updated treatment recommendations.

The baseline demographic and disease characteristics of the patients analyzed in our study provide interesting insights. The prevalence of cigarette smoking (approximately 30\% in both the total COPD population and GOLD Stage 2 subset) is rather high considering that smoking cessation is the single most important intervention for all COPD patients who continue to smoke and has the greatest capacity to influence the natural history of the disease. ${ }^{1}$ The prevalence of anxiety or depression was also approximately $30 \%$ in both study populations. This may be expected to influence treatment outcomes because depression, in particular, is associated with poor compliance and negatively impacts on smoking cessation. ${ }^{46}$ The proportion of patients with a history of pneumonia increased steadily from GOLD Groups A (6.2\%) through D (11.9\%), which is as expected and supports the reliability of GOLD Group categorization in the study. The majority of patients in Groups C and D were classified in these groups based on their severity of airflow limitation rather than exacerbation history, which is in accordance with the findings of other cohort studies. ${ }^{47}$

Although it is often reported that most COPD patients remain undiagnosed until their disease progresses to severe stages $\left(\mathrm{FEV}_{1}<50 \%\right.$ predicted $),{ }^{48-50}$ in our study more than $50 \%$ of patients with spirometry-confirmed COPD had GOLD Stage 2 disease. This is consistent with other retrospective cohort studies in the UK. A recent analysis of a large database of primary-care COPD patients from 80 general practices across the UK showed that GOLD Stage 2 disease was present in $52 \%$ of patients. ${ }^{51}$ In an analysis of primaryand secondary-care data pooled from the OPCRD and the General Practice Research Database, $45 \%$ of patients with $\mathrm{FEV}_{1}$ data available had GOLD Stage 2 disease. ${ }^{52}$ The proportion of patients with a lesser degree of airflow obstruction 
at the time of COPD diagnosis increased over the 20-year study period, which may be due to increased use of diagnostic spirometry and recent COPD policy and practice guidance aimed to improve COPD diagnosis. ${ }^{52}$

Several study limitations must be considered when interpreting our results. As this is a retrospective analysis, it is not possible to conclude whether the treatment patterns are a response to symptoms or whether the symptoms show lack of response to treatment. Further, data on adherence have not been analyzed, so it cannot be established whether the presence of symptoms in patients on treatment is owing to inadequate disease control as a result of suboptimal treatment or poor adherence to prescribed medications, or both. The analyses using CAT scores were conducted in a subset of patients because, unlike $\mathrm{mMRC}$ scores that were determined from questionnaire data or patient records, CAT scores could only be calculated from patient questionnaires, which were not available for all patients. Potential differences between the characteristics of patients who returned questionnaires and those who did not cannot be discounted as a possible source of bias.

In summary, this analysis of UK prescribing patterns indicates that COPD management choices do not usually follow GOLD recommendations and NICE guidelines, in particular those relating to the use of ICS and long-acting bronchodilators, which results in a substantial proportion of patients not being treated or not receiving the most appropriate medication. Further, it has been shown that many patients experience symptoms despite treatment. In light of the evidence provided by this analysis, evidence-based prescription of COPD therapies should be encouraged among UK primary-care physicians in order to limit the risks and costs associated with undertreatment and overtreatment and to improve patient outcomes.

\section{Acknowledgments}

The analyses reported in this manuscript were funded by Novartis Pharma AG (Basel, Switzerland) and were conducted by Research in Real-Life Ltd (Cambridge, UK), an independent company. The authors were assisted in the preparation of the manuscript by Roberta Sottocornola, a professional medical writer contracted to CircleScience (Tytherington, UK), part of KnowledgePoint360, an Ashfield Healthcare Communications (Ashby de la Zouch, UK) company. Writing support was funded by Novartis Pharma AG.

\section{Disclosure}

DP has served on advisory boards for Aerocrine, Almirall, Amgen, AstraZeneca, Boehringer Ingelheim, Chiesi, Meda,
Mundipharma, Napp, Novartis, and Teva. He has consultant arrangements with Almirall, Amgen, AstraZeneca, Boehringer Ingelheim, Chiesi, GlaxoSmithKline, Meda, Mundipharma, Napp, Novartis, Pfizer, and Teva. He or his research team has received grants (or grants pending) and support for research in respiratory disease from the following organizations in the last 5 years: UK National Health Service, British Lung Foundation, Aerocrine, AstraZeneca, Boehringer Ingelheim, Chiesi, Eli Lilly, GlaxoSmithKline, Meda, Merck, Mundipharma, Novartis, Orion, Pfizer, Respiratory Effectiveness Group, Takeda, Teva, and Zentiva. $\mathrm{He}$ has received unrestricted funding for investigatorinitiated studies from Aerocrine, AKL Ltd, Almirall, Boehringer Ingelheim, Chiesi, Meda, Mundipharma, Napp, Novartis, Orion, Takeda, Teva, and Zentiva. He has received funding for patient enrollment or completion of research from Almirall, Chiesi, Teva, and Zentiva. He has received payments for lectures/speaking from Almirall, AstraZeneca, Boehringer Ingelheim, Chiesi, Cipla, GlaxoSmithKline, Kyorin, Meda, Merck, Mundipharma, Novartis, Pfizer, Skyepharma, Takeda, and Teva; travel/accommodations/ meeting expenses from Aerocrine, Boehringer Ingelheim, Mundipharma, Napp, Novartis, and Teva; manuscript preparation from Mundipharma and Teva; and development of educational materials from GlaxoSmithKline and Novartis. He has patents and shares with AKL Ltd and owns $80 \%$ of Research in Real-Life Ltd and its subsidiary social enterprise Optimum Patient Care.

GB has received lecture fees from AstraZeneca, Boehringer Ingelheim, Chiesi, GlaxoSmithKline, Novartis, and Pfizer. He is a member of advisory boards for AstraZeneca, Boehringer Ingelheim, GlaxoSmithKline, and Novartis.

KG-J has spoken on behalf of, or acted as a consultant for, Almirall, Chiesi, AstraZeneca, GlaxoSmithKline, Boehringer Ingelheim, Merck Sharp \& Dohme, Napp/Mundipharma, and Novartis.

RJ has been paid to take part in educational activities related to COPD for Almirall, AstraZeneca, Boehringer Ingelheim, Chiesi, GlaxoSmithKline, Novartis, Nutricia, and Pfizer in the last 3 years. He is consultant to COPDexchange educational programs supported by Boehringer Ingelheim, to the iCOPD project supported by Almirall, and to Health Intelligence.

MM has received speaker fees from AstraZeneca, Bayer Schering, Boehringer Ingelheim, Merck Sharp and Dohme, Novartis, Pfizer, Takeda-Nycomed, and Talecris-Grifols and consulting fees from Almirall, AstraZeneca, Bayer Schering, Boehringer Ingelheim, GlaxoSmithKline, Merck Sharp 
and Dohme, Novartis, Pfizer, Talecris-Grifols, and TakedaNycomed.

AR has received reimbursement for attending symposia, fees for speaking, fees for organizing education, funds for research, and fees for consulting from AstraZeneca, Boehringer Ingelheim/Pfizer, Chiesi, GlaxoSmithKline, Novartis, and Nycomed/Tanaka.

DW, CH, VLA, RS, and KB are employees of Research in Real-Life Ltd, which has conducted paid research in respiratory disease on behalf of the following organizations in the past 5 years: Aerocrine, AKL Ltd, Almirall, Boehringer Ingelheim, Chiesi, GlaxoSmithKline, Meda, Mundipharma, Napp, Novartis, Orion, Takeda, Teva, Zentiva.

\section{References}

1. Global Initiative for Chronic Obstructive Lung Disease (GOLD 2014). Global Strategy for the Diagnosis, Management, and Prevention of Chronic Obstructive Pulmonary Disease: Updated 2014. Global Initiative for Chronic Obstructive Lung Disease; 2014. Available from: http://www.goldcopd.org/uploads/users/files/GOLD_Report_2014.pdf. Accessed June 18, 2014.

2. National Institute for Health and Care Excellence. NICE Guidelines [CG101]: Chronic Obstructive Pulmonary Disease: Management of Chronic Obstructive Pulmonary Disease in Adults in Primary and Secondary Care (Partial Update). London: National Institute for Health and Care Excellence; 2010. Available from: http://www.nice.org.uk/ guidance/CG101. Accessed June 18, 2014.

3. Cazzola M, Matera MG. Long-acting bronchodilators are the first-choice option for the treatment of stable COPD. Chest. 2004;125(1):9-11.

4. Vogelmeier C, Kardos P, Harari S, Gans SJ, Stenglein S, Thirlwell J. Formoterol mono- and combination therapy with tiotropium in patients with COPD: a 6-month study. Respir Med. 2008;102(11):1511-1520.

5. Van Noord JA, Aumann JL, Janssens E, et al. Combining tiotropium and salmeterol in COPD: effects on airflow obstruction and symptoms. Respir Med. 2010;104(7):995-1004.

6. Mahler DA, D’Urzo A, Bateman ED, et al. Concurrent use of indacaterol plus tiotropium in patients with COPD provides superior bronchodilation compared with tiotropium alone: a randomised, doubleblind comparison. Thorax. 2012;67(9):781-788.

7. Bateman ED, Ferguson GT, Barnes N, et al. Dual bronchodilation with QVA149 versus single bronchodilator therapy: the SHINE study. Eur Respir J. 2013;42(6):1484-1494.

8. Antón E. How and when to use inhaled corticosteroids in chronic obstructive pulmonary disease? Expert Rev Respir Med. 2013; 7(Suppl 2):25-32.

9. Miravitlles M, Soler-Cataluña JJ, Calle M, et al. A new approach to grading and treating COPD based on clinical phenotypes: summary of the Spanish COPD guidelines (GesEPOC). Prim Care Respir J. 2013;22(1):117-121.

10. Postma DS, Calverley P. Inhaled corticosteroids in COPD: a case in favour. Eur Respir J. 2009;34(1):10-12.

11. Suissa S, Barnes PJ. Inhaled corticosteroids in COPD: the case against. Eur Respir J. 2009;34(1):13-16.

12. Price D, Yawn B, Brusselle G, Rossi A. Risk-to-benefit ratio of inhaled corticosteroids in patients with COPD. Prim Care Respir J. 2013;22(1):92-100.

13. Nannini LJ, Lasserson TJ, Poole P. Combined corticosteroid and longacting beta(2)-agonist in one inhaler versus long-acting beta(2)-agonists for chronic obstructive pulmonary disease. Cochrane Database Syst Rev. 2012;9:CD006829.
14. Crim C, Calverley PM, Anderson JA, et al. Pneumonia risk in COPD patients receiving inhaled corticosteroids alone or in combination: TORCH study results. Eur Respir J. 2009;34(3):641-647.

15. Suissa S. Author's response to letter on number needed to treat in COPD: exacerbations versus pneumonias. Thorax. 2013;68(9):882-883.

16. Kim JH, Park JS, Kim KH, Jeong HC, Kim EK, Lee JH. Inhaled corticosteroid is associated with an increased risk of TB in patients with COPD. Chest. 2013;143(4):1018-1024.

17. Corrado A, Rossi A. How far is real life from COPD therapy guidelines? An Italian observational study. Respir Med. 2012;106(7):989-997.

18. Fitch K, Iwasaki K, Pyenson B, Plauschinat C, Zhang J. Variation in adherence with Global Initiative for Chronic Obstructive Lung Disease (GOLD) drug therapy guidelines: a retrospective actuarial claims data analysis. Curr Med Res Opin. 2011;27(7):1425-1429.

19. Jebrak G. [COPD routine management in France: are guidelines used in clinical practice?]. Rev Mal Respir. 2010;27(1):11-18. French [with English abstract].

20. Jochmann A, Neubauer F, Miedinger D, et al. General practitioners' adherence to the COPD GOLD guidelines: baseline data of the Swiss COPD Cohort Study. Swiss Med Wkly. Epub April 21, 2010.

21. Jones RC, Dickson-Spillmann M, Mather MJ, Marks D, Shackell BS. Accuracy of diagnostic registers and management of chronic obstructive pulmonary disease: the Devon primary care audit. Respir Res. 2008;9:62.

22. Lucas AE, Smeenk FW, Smeele IJ, van Schayck CP. Overtreatment with inhaled corticosteroids and diagnostic problems in primary care patients, an exploratory study. Fam Pract. 2008;25(2):86-91.

23. Global Initiative for Chronic Obstructive Lung Disease (GOLD 2007). Global Strategy for the Diagnosis, Management, and Prevention of Chronic Obstructive Pulmonary Disease: Updated December 2007. Global Initiative for Chronic Obstructive Lung Disease; 2007. Available from: http:/www.goldcopd.org/uploads/users/files/ GOLDReport07_0108.pdf. Accessed June 18, 2014.

24. British Medical Association. 2014/15 General Medical Services (GMS) Contract Quality and Outcomes Framework (QOF). London: British Medical Association; 2014. Available from: http://bma.org.uk/practicalsupport-at-work/contracts/independent-contractors/qof-guidance. Accessed June 18, 2014.

25. Jones PW, Harding G, Berry P, Wiklund I, Chen WH, Kline Leidy N. Development and first validation of the COPD Assessment Test. Eur Respir J. 2009;34(3):648-654.

26. Global Initiative for Chronic Obstructive Lung Disease (GOLD 2013). Global Strategy for the Diagnosis, Management, and Prevention of Chronic Obstructive Pulmonary Disease: Updated 2013. Global Initiative for Chronic Obstructive Lung Disease; 2013. Available from: http://www.goldcopd.org/uploads/users/files/GOLD_Report_2013_ Feb20.pdf. Accessed June 18, 2014.

27. Hill SC, Miller GE, Sing M. Adults with diagnosed and untreated diabetes: who are they? How can we reach them? J Health Care Poor Underserved. 2011;22(4):1221-1238.

28. Avasarala JR, O'Donovan CA, Roach SE, Camacho F, Feldman SR. Analysis of NAMCS data for multiple sclerosis, 1998-2004. BMC Med. 2007;5:6.

29. Gavras HP. Issues in hypertension: drug tolerability and special populations. Am J Hypertens. 2001;14(7 Pt 2):231S-236S.

30. Harris Interactive. Many Who Suffer From Multiple Sclerosis (MS) Are Not Getting Treatment They Could Benefit From. 2001. Available from: http://www.mult-sclerosis.org/news/May2001/ HarrisPollPwMSundertreated.html. Accessed June 18, 2014.

31. Wong ND, Lopez VA, L'Italien G, Chen R, Kline SE, Franklin SS. Inadequate control of hypertension in US adults with cardiovascular disease comorbidities in 2003-2004. Arch Intern Med. 2007; 167(22):2431-2436.

32. Franssen FM, Spruit MA, Wouters EF. Determinants of polypharmacy and compliance with GOLD guidelines in patients with chronic obstructive pulmonary disease. Int J Chron Obstruct Pulmon Dis. 2011;6:493-501. 
33. Small M, Broomfield S, Higgins V. Quantification and treatment patterns of real-world patients classified by the GOLD 2011 strategy. Poster presented at: 22nd Annual Congress of the European Respiratory Society; September 1-5; 2012; Vienna, Austria.

34. Decramer M, Bartsch P, Pauwels R, Yernault JC. Management of COPD according to guidelines. A national survey among Belgian physicians. Monaldi Arch Chest Dis. 2003;59(1):62-80.

35. Glaab T, Banik N, Rutschmann OT, Wencker M. National survey of guideline-compliant COPD management among pneumologists and primary care physicians. COPD. 2006;3(3):141-148.

36. Miravitlles M, Brosa M, Velasco M, et al. An economic analysis of pharmacological treatment of COPD in Spain. Respir Med. 2009;103(5): 714-721.

37. Miravitlles M, Andreu I, Romero Y, Sitjar S, Altés A, Anton E. Difficulties in differential diagnosis of COPD and asthma in primary care. Br J Gen Pract. 2012;62(595):e68-e75.

38. Perez X, Wisnivesky JP, Lurslurchachai L, Kleinman LC, Kronish IM. Barriers to adherence to COPD guidelines among primary care providers. Respir Med. 2012;106(3):374-381.

39. Salinas GD, Williamson JC, Kalhan R, et al. Barriers to adherence to chronic obstructive pulmonary disease guidelines by primary care physicians. Int J Chron Obstruct Pulmon Dis. 2011;6:171-179.

40. Pearson M, Ayres JG, Sarno M, Massey D, Price D. Diagnosis of airway obstruction in primary care in the UK: the CADRE (COPD and Asthma Diagnostic/management REassessment) programme 1997-2001. Int J Chron Obstruct Pulmon Dis. 2006;1(4):435-443.

41. White P, Thornton H, Pinnock H, Georgopoulou S, Booth HP. Overtreatment of COPD with inhaled corticosteroids - implications for safety and costs: cross-sectional observational study. PLoS One. 2013;8(10):e75221.

42. Brusasco V, Hodder R, Miravitlles M, Korducki L, Towse L, Kesten S. Health outcomes following treatment for six months with once daily tiotropium compared with twice daily salmeterol in patients with COPD. Thorax. 2003;58(5):399-404.
43. Casaburi R, Mahler DA, Jones PW, et al. A long-term evaluation of once-daily inhaled tiotropium in chronic obstructive pulmonary disease. Eur Respir J. 2002;19(2):217-224.

44. Donohue JF, van Noord JA, Bateman ED, et al. A 6-month, placebo-controlled study comparing lung function and health status changes in COPD patients treated with tiotropium or salmeterol. Chest. 2002;122(1):47-55.

45. Donohue JF, Kalberg C, Emmett A, Merchant K, Knobil K. A shortterm comparison of fluticasone propionate/salmeterol with ipratropium bromide/albuterol for the treatment of COPD. Treat Respir Med. 2004;3(3):173-181.

46. Wilson I. Depression in the patient with COPD. Int J Chron Obstruct Pulmon Dis. 2006;1(1):61-64.

47. Agusti A, Hurd S, Jones P, et al. FAQs about the GOLD 2011 assessment proposal of COPD: a comparative analysis of four different cohorts Eur Respir J. 2013;42(5):1391-1401.

48. Bednarek M, Maciejewski J, Wozniak M, Kuca P, Zielinski J. Prevalence, severity and underdiagnosis of COPD in the primary care setting. Thorax. 2008;63(5):402-407.

49. Mapel DW, Dalal AA, Blanchette CM, Petersen H, Ferguson GT. Severity of COPD at initial spirometry-confirmed diagnosis: data from medical charts and administrative claims. Int J Chron Obstruct Pulmon Dis. 2011;6:573-581.

50. Soriano JB, Zielinski J, Price D. Screening for and early detection of chronic obstructive pulmonary disease. Lancet. 2009;374(9691): 721-732.

51. Haughney J, Gruffydd-Jones K, Roberts J, Lee AJ, Hardwell A, McGarvey L. The distribution of COPD in UK general practice using the new GOLD classification. Eur Respir J. 2014;43(4): 993-1002.

52. Jones RC, Price D, Ryan D, et al. Opportunities to diagnose chronic obstructive pulmonary disease in routine care in the UK: a retrospective study of a clinical cohort. Lancet Respir Med. 2014;2(4): $267-276$. 


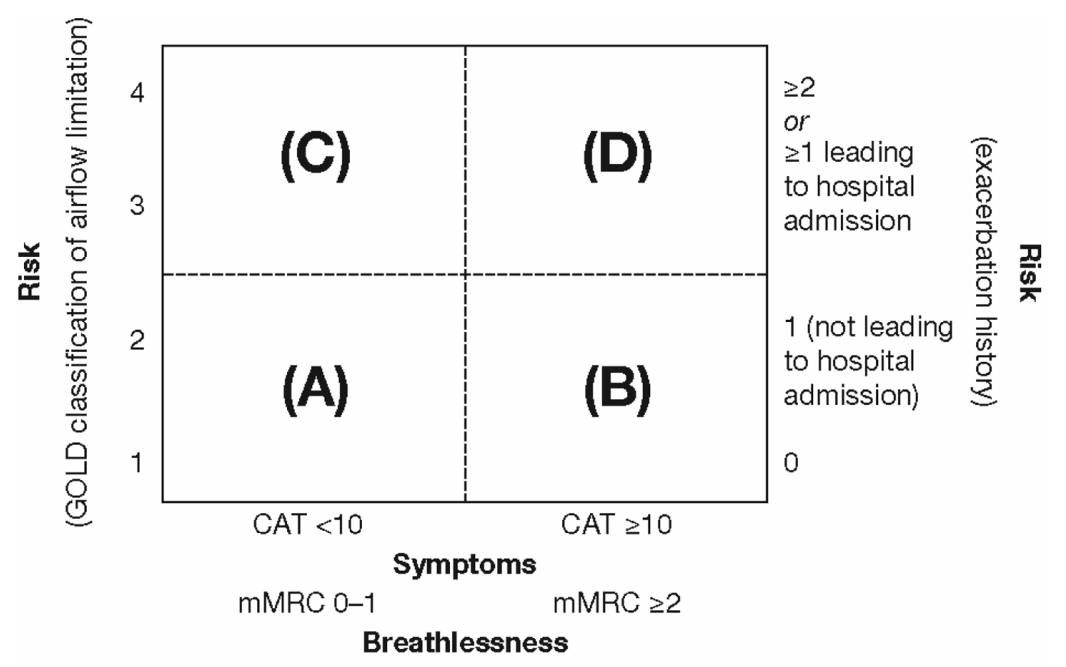

\begin{tabular}{cccccc}
$\begin{array}{c}\text { Patient } \\
\text { category }\end{array}$ & \multicolumn{1}{c}{ Characteristics } & $\begin{array}{c}\text { Spirometric } \\
\text { classification }\end{array}$ & $\begin{array}{c}\text { Exacerbations } \\
\text { per year }\end{array}$ & CAT & mMRC \\
\hline A & Low risk, less symptoms & GOLD 1-2 & $\leq 1$ & $<10$ & $0-1$ \\
B & Low risk, more symptoms & GOLD 1-2 & $\leq 1$ & $\geq 10$ & $\geq 2$ \\
C & High risk, less symptoms & GOLD 3-4 & $\geq 2$ & $<10$ & $0-1$ \\
D & High risk, more symptoms & GOLD 3-4 & $\geq 2$ & $\geq 10$ & $\geq 2$ \\
\hline
\end{tabular}

Figure SI Model of symptom/risk evaluation of COPD.

Notes: When assessing risk, choose the highest risk according to GOLD stage or exacerbation history (one or more hospitalizations for COPD exacerbations should be considered high risk). GOLD I, 2, 3, and 4 correspond to mild ( $F E V_{1} \geq 80 \%$ predicted), moderate $(50 \% \leq \mathrm{FEV},<80 \%$ predicted), severe ( $30 \% \leq \mathrm{FEV},<50 \%$ predicted), and very severe ( $\mathrm{FEV}_{1}<30 \%$ predicted) airflow limitation, respectively. Reproduced from the Global Strategy for Diagnosis, Management and Prevention of COPD 2014. Copyright (C) Global Initiative for Chronic Obstructive Lung Disease (GOLD), all rights reserved. Available from http://www.goldcopd.org.'

Abbreviations: CAT, COPD Assessment Test; COPD, chronic obstructive pulmonary disease; FEV , forced expiratory volume in I second; GOLD, Global Initiative for Chronic Obstructive Lung Disease; mMRC, modified Medical Research Council.

\begin{tabular}{|c|c|c|}
\hline \multicolumn{3}{|c|}{ Please tick in the box that applies to you (one box only) } \\
\hline mMRC Grade 0 & I only get breathless with strenuous exercise. & $\Gamma$ \\
\hline mMRC Grade 1 & $\begin{array}{l}\text { I get short of breath when hurrying on the level or walking up a } \\
\text { slight hill. }\end{array}$ & $\Gamma$ \\
\hline mMRC Grade 2 & $\begin{array}{l}\text { I walk slower than people of the same age on the level because of } \\
\text { breathlessness, or I have to stop for breath when walking on my } \\
\text { own pace on the level. }\end{array}$ & $\Gamma$ \\
\hline mMRC Grade 3 & $\begin{array}{l}\text { I stop for breath after walking about } 100 \text { meters or after a few } \\
\text { minutes on the level. }\end{array}$ & $\Gamma$ \\
\hline mMRC Grade 4 & $\begin{array}{l}\text { I am too breathless to leave the house or I am breathless when } \\
\text { dressing or undressing. }\end{array}$ & $\Gamma$ \\
\hline
\end{tabular}

Figure S2 Modified Medical Research Council questionnaire for assessing the severity of breathlessness.

Reproduced from the Global Strategy for Diagnosis, Management and Prevention of COPD 20I4. Copyright (C) Global Initiative for Chronic Obstructive Lung Disease (GOLD), all rights reserved. Available from http://www.goldcopd.org.'

Abbreviation: mMRC, modified Medical Research Council. 


\section{How is your COPD? Take the COPD Assessment Test ${ }^{\mathrm{TM}}$ (CAT)}

This questionnaire will help you and your healthcare professional measure the impact COPD (Chronic Obstructive Pulmonary Disease) is having on your well-being and daily life. Your answers, and test score, can be used by you and your healthcare professional to help improve the management of your COPD and get the greatest benefits from treatment.

For each item below, place a mark $(\mathbf{X})$ in the box that best describes you currently. Be sure to only select one response for each question

\begin{tabular}{|c|c|c|}
\hline Example: I am very happy & I am very sad & Score \\
\hline I never cough & I cough all the time & \\
\hline $\begin{array}{l}\text { I have no phlegm (mucus) } \\
\text { in my chest at all }\end{array}$ & $\begin{array}{l}\text { My chest is completely } \\
\text { full of phlegm (mucus) }\end{array}$ & \\
\hline $\begin{array}{l}\text { My chest does not feel } \\
\text { tight at all }\end{array}$ & My chest feels very tight & \\
\hline $\begin{array}{l}\text { When I walk up a hill or } \\
\text { one flight of stairs I am } \\
\text { not breathless }\end{array}$ & $\begin{array}{l}\text { When I walk up a hill or } \\
\text { one flight of stairs I am } \\
\text { very breathless }\end{array}$ & \\
\hline $\begin{array}{l}\text { I am not limited doing } \\
\text { any activities at home }\end{array}$ & $\begin{array}{l}\text { I am very limited doing } \\
\text { activities at home }\end{array}$ & \\
\hline $\begin{array}{l}\text { I am confident leaving } \\
\text { my home despite my } \\
\text { lung condition }\end{array}$ & $\begin{array}{l}\text { I am not at all confident } \\
\text { leaving my home because } \\
\text { of my lung condition }\end{array}$ & \\
\hline I sleep soundly & $\begin{array}{l}\text { I do not sleep soundly } \\
\text { because of my lung } \\
\text { condition }\end{array}$ & \\
\hline I have lots of energy & I have no energy at all & \\
\hline & $\begin{array}{l}\text { Total } \\
\text { score }\end{array}$ & \\
\hline
\end{tabular}

Figure S3 COPD Assessment Test.

Notes: The COPD Assessment Test score is calculated as the sum of the responses present. If more than two responses are missing, a score cannot be calculated; when one or two items are missing their scores can be set to the average of the nonmissing item scores. Reproduced with permission. COPD Assessment Test and CAT logo is a trade mark of the GlaxoSmithKline group of companies. () 2009 GlaxoSmithKline group of companies. All rights reserved. ${ }^{2}$

\section{References}

1. Global Initiative for Chronic Obstructive Lung Disease (GOLD 2014). Global Strategy for the Diagnosis, Management, and Prevention of Chronic Obstructive Pulmonary Disease: Updated 2014. Global Initiative for Chronic Obstructive Lung Disease; 2014. Available from: http://www.goldcopd.org/uploads/users/files/GOLD_Report_2014.pdf. Accessed June 18, 2014.
2. Jones PW, Harding G, Berry P, Wiklund I, Chen WH, Kline Leidy N. Development and first validation of the COPD Assessment Test. Eur Respir J. 2009;34(3):648-654. 
International Journal of COPD

\section{Publish your work in this journal}

The International Journal of COPD is an international, peer-reviewed journal of therapeutics and pharmacology focusing on concise rapid reporting of clinical studies and reviews in COPD. Special focus is given to the pathophysiological processes underlying the disease, intervention programs, patient focused education, and self management protocols.

\section{Dovepress}

This journal is indexed on PubMed Central, MedLine and CAS. The manuscript management system is completely online and includes a very quick and fair peer-review system, which is all easy to use. Visit http://www.dovepress.com/testimonials.php to read real quotes from published authors.

Submit your manuscript here: http://www.dovepress.com/international-journal-of-copd-journal 